\title{
Coals Mines, Repository of Linguistic Diversity.
}

\section{Muhammad Asif ${ }^{1,}$ Dr.Naima Saeed ${ }^{2}$, Dr.Alam Tareen ${ }^{3,}$ Muhammad Ishaq ${ }^{4} \&$ Dr.Amir Ali Abro 5}

${ }^{1}$ MPhil Scholar Sociology, ${ }^{2}$ Assistant professor Department of Criminology University of Karachi.

${ }^{3}$ Assistant professor Department of sociology UoB, Quetta, 4 MPhil Scholar Sociology \& ${ }^{5}$ Assistant Professor Department of sociology, University of Sindh Jamshoro.

\begin{abstract}
:
Balochistan is the largest province of Pakistan in terms of area, and it has long history behind it, the province is mostly mountainous the $70 \%$ of Baluchistan's land is consist of mountains but the province is also rich in agriculture and livestock, the population is less as compare to its area or land and it has scattered population, it also has the world's oldest civilization such as MHER Garh civilization historic and prehistoric evidences prove this statement, the land of Balochistan has seen several kind of invaders in the history, it is gate way to central Asia, the province is rich in archeological sites, the province is well famous regarding its fruits and natural minerals, 39 type of minerals has been exploited in province till 2008, this paper discuss the multiculturalism and bilingualism in especial context of Balochistan, as discussed Balochistan is bucket of several cultures and languages, it is very much rich in the context of culture, the vast area of Balochistan has huge and rich cultures inside it, the Pashtoon and Baloch are the two big nations who have been living on this land for centuries, and both nations have their rich culture in their daily life and both are very much cultural in their daily routine. The natural minerals have been mining before partition, the workers from all over the country are found on this land even large number of workers also come from the neighbor country Afghanistan, coal mining is carried out in six districts of Balochistan where workers have been mining, there major number of workers can be found from KPK province and also there are enough number of workers who belong to
\end{abstract}


Hazara tribe who speak Hazargi language and they have their own language and culture, in Mach coal fields the several languages and cultures are found.

Key words: Coal Mine, Worker, Repository, Languages.

\section{Introduction:}

The theme of global village has an integral acceptance that our globe belongs to all cultures without any prejudice, the Pakistan is multicultural country and same is the case with its provinces, no doubt the provinces are also multicultural and multilingual, the earth has different type of species but the human are only specie that have their culture, because human is the only creature who is called social animals due to its speaking, thinking and cultural characteristics, this is also human characteristics that can speak more than one language and have its specific cultures for its happiness or sorrows, the human societies have their specific cultures and languages, because the geographical changes effect on human societies and on their culture and languages, it effects the material and non-material cultures and the symbolic culture also differs but however there are few universal cultures which are implemented in all over the globe. As mentioned above that this paper discussed the multiculturalism and bilingualism in Balochistan.

Pakistan has different type of cultures inside it, the all provinces including Azad Kashmir, Gilgit Baltistan and Federal administered areas (FATA) have different cultures and languages, the only one language which combines whole the nation that is Urdu and English which is mostly used as official language and language of understanding.

Balochistan has diverse cultural zones and ethnically different traditional societies, the province has different type of multicultural and bilingual societies, mainly the languages which are spoken in province are Balochi, Pashto and Brahui but Sindhi, Persian, Uzbaki, Punjabi, are also spoken in all over the province however Pashto, Balochi and Brahui are the major languages in spoken in province, all these have their specific and separate historical, linguistic and cultural identities in large ethno societies for centuries they have protected their distinct identities, the 
oldest occupants of central Balochistan are called Brahuies who belong to Dravidians and have their own culture, language and identity (sabir, A. R., \& Razzaq,2010), but the Pashto language is spoken in all over the Pakistan and Afghanistan, there are large number of people who speak Balochi such as in Pakistan, Iran and Afghanistan.

\section{Coal Mine Workers And Language Diversity:}

There are six big coal fields in Balochistan such as Shahrag coal fields, Chamallang coal fields, Degari coal fields, Duki coal fields, Sorange coal fields and Mach coal fields. in these all above coal fields the workers come from all over the country mostly form KPK province but after the military operation started in tribal area or the operation Zarb e Azb has been initiated the people from south and north Waziristan are also working in coal fields now a days, but in Mach coal fields the workers belong to KPK, and Balochistan province however the workers from Afghanistan are as well engaged in mining at Mach coal fields.

\begin{tabular}{||llll||}
\hline \hline S/NO & PROVINCE & FREQUENCY & PERCENTAGE \\
1 & BALOCHISTAN & 123 & $61.5 \%$ \\
2 & KPK & 77 & $38.5 \%$ \\
& TOTAL & 200 & $100 \%$ \\
\hline
\end{tabular}

The above table shows the percentage of workers who belong to KPK and Balochistan province, among 300 workers from Mach coal fields the 100 workers belong to Afghanistan, the following table shows the percentage of workers nationality.

\begin{tabular}{|llll||}
\hline S/NO & NATIONALITY & FREQUENCY & PERCENTAGE \\
1 & PAKISTANI & 200 & $67.0 \%$ \\
2 & AFGHANI & 100 & $33.0 \%$ \\
& TOTAL & 300 & $100 \%$ \\
\hline \hline
\end{tabular}

The above table shows that there are several types of workers who work in coal fields where they share different type of language and cultures. 


\section{The Workers Type:}

In coal mine fields there are different type of workers inside the coal fields, in coal fields the role of workers are defined, there are workers who just work inside the coal mine they are excavator the other workers who are called loader they work inside and also outside the coal mine, they also load the big or long vehicles for transportation.

\begin{tabular}{||llll||}
\hline \hline S/No & Workers type & Frequency & Percentage \\
1 & Excavator & 145 & $48.3 \%$ \\
2 & Loader & 106 & $35.2 \%$ \\
3 & Others & 49 & $16.4 \%$ \\
Total & & 300 & $100 \%$ \\
\hline
\end{tabular}

\section{Workers Mother Tongue:}

As mentioned before the diversity of languages is noticed in coal mine workers at Mach coal fields, the workers live far from their families mostly they live nearby the coal fields, the worker share their cultural and social norms with one another. in order to know and study the diversity of languages among the coal mine workers they respondents are asked for their mother tongue that researcher can come to know regarding their primary or first language which they speak at their families.

\begin{tabular}{||llll||}
\hline \hline S/No & Mother Tongue & Frequency & Percentage \\
1 & Sindhi & 12 & $4.0 \%$ \\
2 & Pashto & 142 & $47.3 \%$ \\
3 & Balochi & 9 & $3.0 \%$ \\
4 & Brahui & 49 & $16.3 \%$ \\
5 & Hazargi & 88 & $29.3 \%$ \\
& Total & 300 & $100 \%$ \\
\hline
\end{tabular}

The above table shows that there are several languages spoken at Mach coal fields, and while living under one roof they learn their languages easily, the workers share common roof, food, bathing and many other facilities. 


\section{Interaction between the Respondents:}

Though it is difficult to work or to create health environment at work place where, where the workers belong to different social, cultural and linguistic characteristics

The respondents spend their major time at coal fields, the give their 8 to 10 hours inside the black hole, the workers at coal fields work in different shifts, while inside or outside the coal mine they workers work and live together, respondents do not visit their families soon after a long time they visit their families, the workers live and eat together, spend major time with other coal workers means with their roommates. Respondents visit Mach Bazar on Fridays (Friday is off) for shopping, the workers while having common aims and objectives which makes the respondents close to one another.

\section{Respondents Leisure Time Activities:}

Due to multi-cultural and multilingual coal mine workers the respondents have different type of leisure activities, in order to have rest after spending 8 to 10 hours in coal mine, they workers mostly play Luddo after getting free from mining, majority of the workers do not have television facilities because the coal mines are situated in barren areas where television signals are not found even in large number of coal fields the mobile signals are also not found due to mountainous areas.

In such a situation the workers have to entertain with one another while creating different type of leisure activities, the large number of workers also listen radio where they enjoy their cultural and linguistic songs, in spite this the workers have gatherings at meal time and tea time where mostly they sing songs in their native languages where they transfer their languages and learn one another languages and cultural norms, the workers play the cultural indoor game also which is locally called ( Kattar) which does not need some special instruments it just needs few stones to be played, the mostly have gatherings after work or the shift finishes, due to unavailability of media tools the workers spend their leisure time while creating several type of activities where they can entertain themselves. 


\section{Language Diversity among the Workers:}

While conduction this study the language diversity is noticed among the coal mine workers, as mentioned above due to living under one common roof the workers share their language, social and cultural characteristics, according to this study the Pashto is the dominant and common language at coal fields and there the different accent of Pashto is spoken because the workers from KPK province have their especial and specific accent in speaking but other Pashton workers who belong to Balochistan and Afghanistan their accent is different than those but however the Pashto language is spoken by both the causes of Pashtu language dominancy is because the respondents who belong to Hazara community, Baloch community or Sindhi community they can speak Pashto fluently accept this the second common language is Brahui which is spoken by many other those whose primary language is not Brahui, mostly Sindhi and Balochi speaking workers speak Brahui as second language, and these workers also can speak Pashto and Hazargi, those workers whose primary language is Brahui they also can speak Pashto, Persian, Balochi and even Hazargi fluently due to diversity in their languages and spending major time with each other, according to one respondent that while working in coal fields they interact with different type of workers and community as well, where they learn their languages, and even the community also can speak our languages while giving the example of one doctor that he can speak Pashto and Hazargi fluently.

The following table shows the frequency and percentage of workers who are bilingual or even multilingual due to coal mining,

\begin{tabular}{||llll||}
\hline \hline S/No & Languages & Frequency & Percentage \\
1 & Monolingual & 57 & $19 \%$ \\
2 & Bilingual & 149 & $50 \%$ \\
3 & Multilingual & 94 & $31 \%$ \\
Total & & 300 & $100 \%$ \\
\hline
\end{tabular}


The above table shows clearly that major percentage of respondents is bilingual and also huge percentage of workers is multilingual the only $19 \%$ workers are monolingual; these respondents are mostly from remote areas of Mach town and those. Who have recently joined this occupation? And mostly the young age respondents or can say the child labour can speak just their primary language.

The following contingency table shows the data of respondents secondary languages which they can speak other than their mother tongue or primary languages.

\section{Social Gatherings at Coal Fields}

As discussed in detail that coal mine workers spend most of the time together and they participate the social gatherings also such as the different cultural ceremonies arranged by the workers which is also one of the major reasons for learning and sharing their cultural norms, according to respondents thy mostly visit those workers or their communities who live nearby the coal fields who are the local citizens of Tehsil Mach or those shopkeepers invite them in their cultural and social gatherings from where the respondents mostly do shopping. The following table shows the percentage of workers who attend social gatherings.

\begin{tabular}{||llll||}
\hline S/No & Social Gatherings & Frequency & Percentage \\
1 & Yes & 243 & $81 \%$ \\
2 & No & 57 & $19 \%$ \\
& Total & 300 & $100 \%$ \\
\hline
\end{tabular}

\section{Community Welfare Activities}

The workers in Mach coal fields do not have labour unions because the labour department does not have any concern with these labours and they are hired by the contractor where they agree on terms and conditions on coal mining, but those respondents who live and share work in one coal field or those workers who work in other coal fields nearby them, in emergency situation 
the workers help one another and mostly they take them to the hospitals towards Sibi or Quetta the capital, for the benefit of workers they interact with each other in order to have safe and healthy working environment. The following table shows the percentage of workers who participate in community welfare activities.

\begin{tabular}{||ccll||}
\hline \hline S/No & Welfare activities & Frequency & Percentage \\
1 & Yes & 255 & $85 \%$ \\
2 & No & 45 & $15 \%$ \\
& Total & 300 & $100 \%$ \\
\hline
\end{tabular}

\section{Working Experience in Coal Mines}

Coal mining is carried out in Tehsil Mach before partition and there are workers who have been working for decades in coal fields, the long working experience is also the reason of multi and bilingualism in coal fields, the following table shows the working experience of respondents.

\begin{tabular}{||llcc||}
\hline \hline S/No & Working Experience & Frequency & Percentage \\
1 & One Year & 53 & $17.6 \%$ \\
2 & 2-3 Years & 52 & $17.3 \%$ \\
3 & 4-5 Years & 45 & $15 \%$ \\
4 & 6-8 Years & 32 & $10.6 \%$ \\
5 & 9-10 Years & 11 & $3.7 \%$ \\
6 & 10-15 Years & 48 & $15.9 \%$ \\
7 & $21-25$ Years & 11 & 3.7 \\
$\mathbf{8}$ & 26-30 Years & 15 & 5.0 \\
$\mathbf{9}$ & $31-35$ Years & 4 & 1.3 \\
$\mathbf{1 0}$ & $36-40$ Years & 1 & .3 \\
\multicolumn{1}{|c}{ Total } & 300 & $100 \%$ \\
\hline
\end{tabular}

The above table shows the reason of learning the secondary languages among the workers, because there are several workers who have been working for 30 to 35 years, the table shows that $15.9 \%$ respondents have been working in coal fields for 10 to 15 years, while spending such a huge time with each other the respondents learn the secondary languages, social and cultural 
norms also, in all the day the workers from different language and culture interact which makes the workers to learn secondary languages.

\section{References}

Sheikh, K. H., \& Arif, G. M. (1989). An Analysis of Rural Homelessness in Pakistan. The Pakistan Development Review, 28(4), 925-935.

Mahmood,S., Sheikh, K. H., Mahmood, T., \& Malik, M. H. (1991). Food Poverty andits Causes in Pakistan [with Comments]. The Pakistan Development Review, 30(4), 821-834.

Sawada, Y., \& Lokshin, M.(1999). Household schooling decision in rural, Pakistan.World Bank Policy Research Working paper, (2541).

Mandal, A. \& Sengupta, D. (2000). The analysis of fatal accidents in Indian coal mines. Calcutta Statistical Association bulletin, 50, 95-118.

Ahasan, M. R., \& Partanen, T. (2001). Occupational Health and Safety in the Least, Developed Countries-A Simple Case of Neglect. Journal of epidemiology, 11(2), 74-80.

Kawakami, T., \& Kogi, K. (2001). Action-oriented support for occupational safety and health programs in some developing countries in Asia. International Journal of Occupational Safety and Ergonomics, 7(4), 421-434.

Finke man, R. B., Orem, W., Castranova, V., Tatu, C. A., Belkin, H. E., Zheng, B., ... \& Bates, A. L. (2002). Health impacts of coal and coal use: possible solutions. International Journal of Coal Geology, 50(1), 425-443.

Husain, F., Qasim, M. A., \& Sheikh, K. H. (2003). An analysis of public

Expenditure on education in Pakistan. The Pakistan development review, 42(4), $771-780$

Ross, M. H., \& Murray, J. (2004). Occupational respiratory disease in mining. Occupational Medicine, 54(5), 304-310.

Donoghue, A. M. (2004). Occupational health hazards in mining: an Overview. Occupational Medicine, 54(5), 283-289.

Agnihotram, R. V. (2005). An overview of occupational health research in India. Indian journal of occupational and Environmental medicine,9(1), 10.(43)Rolfe, J., Ivanova, G., \& Lockie, S. (2006). Assessing the social and 
economic impacts of coal mining on communities in the Bowen Basin: summary and recommendations. Mackay, QLD: Centre for Environmental Management, CQU.

Memon, G. R. (2007). Education in Pakistan: The key issues, problems and the new challenges. Journal of Management and Social Sciences, 3(1), 47-55.

Atkins, A. S., Singh, R. N., \& Pathan, A. G. (2008). Outburst risks in coal mining operations and application of social networks in knowledge management systems. Archives of Mining Sciences, 53(1), 31-52.

Singh, G. (2008). Mitigating environmental and social impacts of coal mining in India. Mining Engineers' Journal, 8-24.

Malik, N., Maan, A. A., Pasha, T. S., Akhtar, S., \& Ali, T. (2010). Role of hazard control measures in occupational health and safety in the textile industry of Pakistan. Pak J Agri Sci, 47(1), 72-76.

Rehman, H., Faridi, M. Z., \& Bashir, F. (2010). Households saving behaviour in Pakistan: A case of Multan district. Pakistan Journal of Social Sciences (PJSS), 30(1), 17-29.

Awan, S., Nasrullah, M., \& Cummings, K. J. (2010). Health hazards, injury problems, and workplace conditions of carpet-weaving children in three districts of Punjab, Pakistan. International journal of occupational and environmental health, 16(2), 113-119.

Pradhan, K., \& Naik, A. K. (2010). Impact of Industrial Environment on Socioeconomic Conditions of Mine Workers: A study of Coal Industries in Odisha.

Akram, W., Naz, I., \& Ali, S. (2011). An Empirical Analysis of

Household Income in Rural Pakistan: Evidences from Tehsil

Samundri. Pakistan Economic and Social Review, 231-249.

Malik, M. S., Basit, A. B., \& Qazi, A. K. (2011). Unions and Management: A Case Study of Pakistan Telecommunication Corporation. Pakistan Journal of Social Sciences (PJSS), 31(1), 185-199.

Hassan, S. A. (2012). Health, safety and environmental practices in the construction sector of Pakistan.

Sabir, A. R., \& Razzaq, W. Multiculturalism: 